\title{
ANALYSIS OF INDUCED QUANTITATIVE VARIATION II. THE RECOMBINANT INBRED LINES
}

\author{
N. R. INGRAM and J. L. JINKS \\ Department of Genetics, University of Birmingham, P.O. Box 363 , \\ Birmingham B15 2TT, U.K.
}

Received 11.ix.81.

\section{SUMMARY}

\begin{abstract}
On average, irradiation of $F_{2}$ seed of the cross of varieties 1 and 5 of Nicotiana rustica increases the additive genetical variation among inbred families in the $\mathrm{F}_{6}$ by about 60 per cent. This agrees with the increase predicted from a hierarchical analysis of $F_{3}$ and $F_{4}$ families but it is greater than that predicted from an $F_{2}$ triple test cross analysis. This is as expected (Virk, Pooni, Ingram and Jinks, 1981). Both predictions, however, overestimate the increase observed in final height but underestimate those for leaf width and flowering time. The underestimates but not the overestimates can be accounted for if irradiation has increased the rate of recombination in the lineages derived from the irradiated $\mathrm{F}_{2}$ seed.

The increased genetical variation following irradiation is accompanied by a shift in the distribution of $F_{6}$ family means towards the lower end; the range of family means is extended and more families have means which are lower than that of the lower scoring parent of the cross. But final height is again unusual in showing a corresponding increase in the range at the upper end of the distribution and more families with means which are higher than that of the taller parent of the cross.
\end{abstract}

\section{INTRODUCTION}

VIRK, Pooni, Ingram and Jinks (1981) estimated, by triple test cross and hierarchical inbreeding analyses, the increase in additive genetical variation induced in the $F_{2}$ of a cross between pure breeding varieties 1 and 5 of Nicotiana rustica by gamma radiation. These estimates have now been used to predict the properties of the recombinant inbred lines that can be derived from the irradiated and non-irradiated $F_{2}$ plants. The properties of the actual inbred lines have been assessed at the $F_{6}$ and $R_{6}$ generations to compare with these predictions.

\section{MATERIALS AND METHOD}

Two randomly chosen plants were selfed from each of the $50 \mathrm{~F}_{4}$ and $\mathrm{RF}_{4}$ families in the 1979 experiment of Virk et al. (1981), and their progenies raised during the following winter. Two randomly chosen plants from each of these $F_{5}$ and $R F_{5}$ families were selfed resulting in a maximum of $200 \mathrm{~F}_{6}$ and $\mathrm{RF}_{6}$ families, that is, $8 \mathrm{~F}_{6}$ or $\mathrm{RF}_{6}$ families from each of the 25 control and irradiated $F_{2}$ seeds. Because of accidental losses the actual number of families in the $F_{6}$ and $R_{F}$ fell short of this maximum by 12 and 11 , respectively, but none of the original $F_{2}$ plants was represented by less than four of the possible eight families. These missing families have subsequently been regenerated but too late to be included in the current assessments. 
The available $88 \mathrm{~F}_{6}$ and $189 \mathrm{RF}_{6}$ families were grown in a completely randomised experiment during the summer of 1980. As additional controls $80 \mathrm{~F}_{15}$ families derived by single seed descent from an $F_{2}$ of the same cross of varieties 1 and 5 (Perkins and Jinks, 1973), the parental varieties themselves and their $F_{1}$ cross were also included in this experiment. Eight individually randomised plants were raised from each of the 460 families. The experiment was scored for leaf width (LW), flowering time (FT), height at flowering time (HFT) and final height (FH) as in the previous experiment.

The variance of the means of the $80 \mathrm{~F}_{15}$ families is a direct estimate of $D$, the additive genetical component of variation. For the $\mathrm{F}_{6}$ and $\mathrm{RF}_{6}$ families the variance of their means is $\frac{15}{16} D+\frac{15}{1024} H$. We can ignore the trivial contribution of the dominance component, $H$ and treat this as an estimate of $\frac{15}{16} D$ from which we can obtain $D$.

\section{RESULTS}

Estimates of $D$ and $E_{w}$, the environmental component of variation, from the $F_{15}, F_{6}$ and $R_{6}$ for each of the four characters are given in table 1. The estimates of $D$ from the $80 F_{15}$ families and the $88 F_{6}$ families

TABLE 1

Estimates of the additive genetical and environmental components of variation for the $F_{6}, R F_{6}$, and $F_{15}$ recombinant inbred lines

\begin{tabular}{|c|c|c|c|c|}
\hline & & $F_{6}$ & $F_{15}$ & $\mathrm{RF}_{6}$ \\
\hline LW & $\begin{array}{c}D \\
E_{w}\end{array}$ & $\begin{array}{r}10 \cdot 9 \pm 1 \cdot 12 \\
7 \cdot 1 \pm 1 \cdot 55\end{array}$ & $\begin{array}{r}11 \cdot 5 \pm 1 \cdot 79 \\
8 \cdot 3 \pm 2 \cdot 26\end{array}$ & $\begin{array}{r}17 \cdot 1 \pm 1 \cdot 76 \\
7 \cdot 1 \pm 1 \cdot 54\end{array}$ \\
\hline FT & $\begin{array}{c}D \\
E_{w}\end{array}$ & $\begin{array}{l}39 \cdot 4+4 \cdot 04 \\
17 \cdot 4 \pm 1 \cdot 77\end{array}$ & $\begin{array}{l}38 \cdot 4 \pm 6 \cdot 00 \\
16 \cdot 6 \pm 2 \cdot 59\end{array}$ & $\begin{array}{l}57 \cdot 9 \pm 6 \cdot 00 \\
15 \cdot 4 \pm 1 \cdot 59\end{array}$ \\
\hline HFT & $\begin{array}{c}D \\
E_{w}\end{array}$ & $\begin{array}{l}271 \cdot 0 \pm 27 \cdot 80 \\
146 \cdot 7 \pm 15 \cdot 05\end{array}$ & $\begin{array}{l}275 \cdot 2 \pm 42 \cdot 98 \\
143 \cdot 0 \pm 22 \cdot 33\end{array}$ & $\begin{array}{l}420 \cdot 2 \pm 43 \cdot 22 \\
145 \cdot 9 \pm 15 \cdot 00\end{array}$ \\
\hline FH & $\begin{array}{l}D \\
E_{w}\end{array}$ & $\begin{array}{l}222 \cdot 1 \pm 22 \cdot 79 \\
174 \cdot 9 \pm 17 \cdot 90\end{array}$ & $\begin{array}{l}192 \cdot 3 \pm 30 \cdot 03 \\
153 \cdot 8 \pm 24 \cdot 03\end{array}$ & $\begin{array}{l}379 \cdot 1 \pm 38 \cdot 89 \\
179 \cdot 9 \pm 18 \cdot 51\end{array}$ \\
\hline
\end{tabular}

are, as expected, very close for all characters the largest difference (FH) having a probability of only 40 to 50 per cent. In contrast the estimates from the $189 \mathrm{RF}_{6}$ families derived from the irradiated $F_{2}$ are all significantly greater than the corresponding estimates from the control $F_{6}$. This increase in variance among $\mathrm{RF}_{6}$ families ranges from 47 per cent for FT to 71 per cent for FH (table 2). The percentage increases in this variance that were expected from the triple test cross and hierarchical analyses of the $F_{2}$ and $\mathrm{RF}_{2}$ (tables 3 and 5, Virk et al., 1981) along with those observed in the $F_{6}$ and $R_{6}$ (table 1) are summarised in table 2.

All three sources correctly predict the largest increase in variation following irradiation for $\mathrm{FH}$ but they all overestimate its magnitude. At the other extreme all three sources of prediction underestimate the increase in variation for LW and FT. For the fourth character HFT the predictions from the hierarchical analyses are good but the triple test cross again gives an underestimate. Over all four characters, therefore, the triple test cross gives predictions as good as, or better than the hierarchical analyses for two characters, FT and FH, but much worse for the other two, LW and 
TABLE 2

Comparison of the percentage increase in the variance of recombinant inbred lines expected following irradiation of the $F_{2}$ with that observed

\begin{tabular}{|c|c|c|c|c|}
\hline \multirow[b]{3}{*}{ Source } & \multicolumn{3}{|c|}{ Expected } & \multirow{3}{*}{$\begin{array}{c}\text { Observed } \\
\mathrm{RF}_{6} / \mathrm{F}_{6}\end{array}$} \\
\hline & \multirow{2}{*}{$\begin{array}{c}\text { Triple } \\
\text { test cross }\end{array}$} & \multicolumn{2}{|c|}{$\begin{array}{l}\text { Hierarchical } \\
\text { inbreeding* }\end{array}$} & \\
\hline & & (1) & (2) & \\
\hline \multicolumn{5}{|l|}{ Character } \\
\hline LW & 1 & 20 & 21 & 57 \\
\hline FT & 26 & 23 & 17 & 47 \\
\hline HFT & 9 & 76 & 55 & 55 \\
\hline FH & 106 & 135 & 112 & 71 \\
\hline
\end{tabular}

* (1) is based on the estimate of $D .(2)$ is based on the estimates of $D_{1}$ and $D_{2}$ and the relative contributions that they make to the total additive genetic variation of recombinant inbred lines.

HFT. Reasons for these differences have been discussed in our earlier paper (Virk et al., 1981) and will be returned to later (section 4).

The value of the increased variation in the $\mathrm{RF}_{6}$ cannot be assessed without reference to the mean of the distribution relative to that of the $F_{6}$ control. The corresponding means for the four characters are, therefore, given in table 3. With the exception of flowering time the mean of the $\mathrm{RF}_{6}$ is lower than that of the $F_{6}$, that is, on average the $R_{6}$ plants are smaller and later flowering but for no character is the difference between the means significant.

The expected means of the $\mathrm{F}_{6}$ and $\mathrm{RF}_{6}$ are $m+\frac{1}{32}[h]$. If we ignore the trivial contribution of $\frac{1}{32}[h]$ we can estimate the $\mathrm{F}_{6}$ and $\mathrm{RF}_{6}$ means from the hierarchical inbreeding experiment as $2 \bar{F}_{4}-\overline{\mathrm{F}}_{3}$ and $2 \overline{\mathrm{RF}}_{4}-\overline{\mathrm{RF}}_{3}$, respectively. The differences between these estimates for the four characters are given in table 4 . They agree with the differences observed for LW, HFT and FH but not for FT but all the expected differences are like those observed, in being non-significant. We neither expect nor observe, therefore, any significant directional changes as a result of mutation.

Not even an approximate estimate of $m$ can be obtained from the families of the $\mathrm{F}_{2}$ or $\mathrm{RF}_{2}$ triple test crosses. We can, however, estimate $m+\frac{1}{2}[h]$ from both which, if we assume $\frac{1}{2}[h]$ is approximately the same for the control and irradiated material, allows us to estimate the difference between the two $m$ 's. These differences are given in table 4. Again all are negative, showing a fall in the expected means of the $\mathrm{RF}_{6}$ relative to those of the $\mathrm{F}_{6}$, but two of them, FT and HFT, are significant.

There are two further ways in which we can examine the outcome in the $\mathrm{F}_{6}$ and $\mathrm{RF}_{6}$; one is to compare the number of families whose means

TABLE 3

The means of the $F_{6}$ and $R F_{6}$ recombinant inbred lines

\begin{tabular}{crrr} 
Character & \multicolumn{1}{c}{ F $_{6}$} & \multicolumn{1}{c}{ RF $_{6}$} & Difference \\
LW & $17.01 \pm 0.75$ & $16.07 \pm 0.85$ & $-0.94 \pm 1.13$ \\
FT & $47.14 \pm 1.25$ & $47.23 \pm 1.39$ & $+0.09 \pm 1.87$ \\
HFT & $76.05 \pm 3.30$ & $74.18 \pm 4.06$ & $-1.87 \pm 5.23$ \\
FH & $131.64 \pm 2.84$ & $129.37 \pm 3.89$ & $-2.27 \pm 4.82$
\end{tabular}


TABLE 4

Differences in the expected means of the $F_{6}$ and $R F_{6}$ predicted from the hierarchical inbreeding and triple test cross experiments

$\begin{array}{ccc}\text { Character } & \text { Hierarchical } & \text { Triple test cross } \\ \text { LW } & -0.21 \pm 0.99 & -0.25 \pm 0.23 \\ \text { FT } & -0.82 \pm 2.35 & -1.38 \pm 0.44 \\ \text { HFT } & -4.32 \pm 6.08 & -2.52 \pm 1.12 \\ \text { FH } & -3.84 \pm 5.99 & -1.62 \pm 1.07\end{array}$

fall outside of the parental range of varieties 1 and 5 (table 5); the other is to compare the ranges of family means (table 6). The frequencies in table 5 are not particularly informative for LW and FT because all of the $\mathrm{F}_{6}$ and $\mathrm{RF}_{6}$ families fall outside of the parental range. The only difference, therefore, is a small shift in the distribution of the $\mathbf{R F}_{6}$ families towards the lower end of the range $\left(<\overline{\mathrm{P}}_{2}\right)$ but for neither character is this significant. For HFT and $\mathrm{FH}$, however, there is a significant increase in the frequency of $\mathrm{RF}_{6}$ relative to $\mathrm{F}_{6}$ families falling outside of the parental range. For HFT this is accompanied by a shift of the distribution towards the lower end of the range but for FH the increase occurs equally at both ends of the distribution. For all characters, therefore, there is an increase in the frequency of families at the lower end of the distribution $\left(<\overline{\mathrm{P}}_{2}\right)$ following irradiation of the $\mathrm{F}_{2}$, but for only one character $\mathrm{FH}$ is there a corresponding increase at the upper end of the distribution $\left(>\overline{\mathrm{P}}_{1}\right)$.

The ranges of $\mathrm{F}_{6}$ and $\mathrm{RF}_{6}$ family means in table 6 give a similar picture. The range is significantly extended at the lower end of the distribution in

TABle 5

The frequency of $F_{6}$ and $R F_{6}$ families whose means fall outside of the parental range of varieties 1 and 5

$\begin{array}{ccccc}\text { Character } & & <\overline{\mathrm{P}}_{2} & >\overline{\mathrm{P}}_{1} & \begin{array}{c}\text { Total outside } \\ \text { parental range }\end{array} \\ \text { LW } & \mathrm{F}_{6} & 124 & 64 & 88 \\ & \mathrm{RF}_{6} & 133 & 56 & 189 \\ \text { FT } & \mathrm{F}_{6} & 52 & 136 & 88 \\ & \mathrm{RF}_{6} & 61 & 128 & 189 \\ \text { HFT } & \mathrm{F}_{6} & 52 & 103 & 155 \\ & \mathrm{RF}_{6} & 79 & 91 & 170 \\ \text { FH } & \mathrm{F}_{6} & 63 & 50 & 113 \\ & \mathrm{RF}_{6} & 75 & 62 & 137\end{array}$

TABLE 6

The range of family means in the $F_{6}$ and $R F_{6}$ generations

\begin{tabular}{|c|c|c|c|}
\hline Character & & Maximum & Minimum \\
\hline LW & $\begin{array}{l}\mathrm{F}_{6} \\
\mathrm{RF}_{6}\end{array}$ & $\begin{array}{l}25.81 \pm 0.48 \\
25.50 \pm 0.91\end{array}$ & $\begin{array}{l}6 \cdot 25 \pm 0 \cdot 58 \\
4 \cdot 17 \pm 0 \cdot 33\end{array}$ \\
\hline FT & $\begin{array}{l}\mathrm{F}_{6} \\
\mathrm{RF}_{6}\end{array}$ & $\begin{array}{l}61 \cdot 88 \pm 1 \cdot 46 \\
62 \cdot 62 \pm 2 \cdot 02\end{array}$ & $\begin{array}{l}36 \cdot 00 \pm 0 \cdot 33 \\
34 \cdot 25 \pm 0 \cdot 31\end{array}$ \\
\hline HFT & $\begin{array}{l}\mathrm{F}_{6} \\
\mathrm{RF}_{6}\end{array}$ & $\begin{array}{l}120 \cdot 57 \pm 3 \cdot 55 \\
117 \cdot 06 \pm 2 \cdot 18\end{array}$ & $\begin{array}{l}45 \cdot 12 \pm 3 \cdot 58 \\
37 \cdot 17 \pm 2 \cdot 08\end{array}$ \\
\hline FH & $\begin{array}{l}\mathrm{F}_{6} \\
\mathrm{RF}_{6}\end{array}$ & $\begin{array}{l}163 \cdot 62 \pm 2.74 \\
167 \cdot 63 \pm 2 \cdot 33\end{array}$ & $\begin{array}{l}78 \cdot 00 \pm 4 \cdot 17 \\
65 \cdot 37 \pm 3 \cdot 82\end{array}$ \\
\hline
\end{tabular}


the $\mathrm{RF}_{6}$ for all four characters. It is extended at the upper end for FT and FH and contracted for LW and HFT but in no case is the difference between the $\mathrm{F}_{6}$ and $\mathrm{RF}_{6}$ significant.

\section{Conclusions}

On average over the four characters studied, irradiation of $F_{2}$ seed has increased the genetical variation among inbred families in the $F_{6}$ by about 60 per cent (table 2). This agrees well with the average predicted increase from the hierarchical analysis although within this average the increase for one character (FH) was overestimated and for two others (LW and FT) underestimated. The average increase predicted from the triple test cross analysis was lower than the 60 per cent observed in the $F_{6}$ but again within this average the increase for $\mathrm{FH}$ was overestimated and those for the remaining three characters underestimated, the predictions for $\mathrm{LW}$ and HFT being particularly low (table 2).

That the triple test cross analysis gives the poorer predictions comes as no surprise since the predictor, the estimate of $D$, is known to be biased by any dominance arising from mutation at loci at which the testers do not differ (Virk et al., 1981). These triple test cross and hierarchical design predictors are however consistent in overestimating the increase for one character and underestimating it for two others and this suggests a common cause. One such possibility is an interaction between the genotypes and seasonal difference between 1979, when the triple test cross and hierarchical experiments were grown, and 1980 , when the $F_{6}$ and $R_{6}$ families were assessed.

A second possibility, that would account for the underestimates for LW, FT and HFT, but not the overestimates for FH, is the repulsion linkages which were detected in the hierarchical experiment (Virk et al., 1981). The linkages themselves could not explain the underestimates but if the irradiation had led to an increase in the rate of recombination in the lineages derived from the $\mathrm{RF}_{2}$ it could account for the unpredictably high increase in the genetical variation in the $\mathrm{RF}_{6}$ relative to that in the $\mathrm{F}_{6}$.

In general the increased genetical variation in the $\mathrm{RF}_{6}$ has led to a higher frequency of inbred families with lower than average means and the occurrence of extreme families with means that are lower than any that can be found in the $F_{6}$ (tables 5 and 6). The only exception is again final height where there is a similar increase in frequency but a smaller increase in range at the upper end of the distribution. On the whole, the predictions from the triple test cross and hierarchical inbreeding analyses are in agreement with these observed directional shifts in the means of the distributions, although few of the predicted changes are significant (table 4).

Acknowledgments. - We acknowledge receipt of an SRC studentship to N.R.I.

\section{REFERENCES}

PERKINS, J. M., AND JINKS, J. L. 1973. The assessment and specificity of environmental and genotype-environmental components of variability. Heredity, 30, 111-126.

VIRK, D. S.. POONI, G. S., INGRAM, N. R., AND JINKS, J. L. 1981. Analysis of induced quantitative variation. I. Hierarchical and triple test cross analysis. Heredity (in the press). 